\title{
UN POEMA MAL ATRIBUIDO AL POETA ANTEQUERANO-GRANADINO AGUSTÍN DE TEJADA PÁEZ
}

\author{
JOSÉ MARÍA DE LA TORRE \\ Catedrático de IES
}

\section{RESUMEN}

Con el descubrimiento del panegírico De Sacrosanctae Virginis Montis Acuti translatione et miraculis panegyris de Juan de Aguilar, se prueba que se le ha atribuido incorrectamente al poeta Agustín de Tejada Páez el poema cuyo primer verso es «El ánimo me inflama ardiente celo», y que figura en el Cancionero antequerano de Ignacio de Toledo y Godoy como suyo, cuando se trata de una traducción al español llevada a cabo por el doctor Tejada. Asimismo, casi todo lo que han escrito sobre dicho poema Dámaso Alonso y el profesor José Lara Garrido es insostenible y refutable a la vista de la obra hallada.

Palabras clave: Hallazgo de De Sacrosanctae Virginis Montis..., panegírico latino, traducción, escuela antequerano-granadina, Cancionero antequerano, estudio comparativo de textos, revisión de lecturas o hipótesis ya formuladas.

\section{A POEM WRONGLY ATTRIBUTED TO THE ANTEQUERA-GRANADA POET AGUSTÍN DE TEJADA PÁEZ}

\begin{abstract}
With the important discovery of the panegyric De Sacrosanctae Virginis Montis Acuti translatione et miraculis panegyris by Juan de Aguilar, it has been proved that the poem, whose first verse is «El ánimo me inflama ardiente celo» and which appears in the Cancionero antequerano» by Ignacio de Toledo y Godoy as a poem by Agustín de Tejada Páez , is a translation into Spanish done by Doctor Tejada and was incorrectly attributed to him. As a consequence, most of what has been written about this poem by Dámaso Alonso and Professor José Lara Garrido has now been disproved.
\end{abstract}

Key words: Discovery of the panegyric De Sacrosanctae Virginis Montis..., translation into Spanish, Cancionero antequerano, most of what has been written about this poem.

\section{INTRODUCCIÓN}

Leyendo, aunque sea superficialmente, las ediciones que, respectivamente, llevaron a cabo sobre el Cancionero antequerano de Ignacio de Toledo y 
Godoy Dámaso Alonso y Rafael Ferreres en $1950^{1}$, por una parte, y treinta y ocho años más tarde (1988) el profesor José Lara Garrido², por otra, se tiene la impresión de que los primeros actuaron precipitadamente y con descuido; en cambio, el trabajo de Lara Garrido se presenta como más concienzudo. Esta sensación aumenta a medida que uno se detiene en la lectura de un poema concreto, como, por ejemplo, el mal atribuido al doctor Agustín de Tejada Páez (1567-1635 $)$ cuyo primer verso reza así: «El ánimo me inflama ardiente celo», y al que le dedicó un extenso comentario el profesor malacitano ${ }^{4}$. Comparando, pues, la lectura que del mismo efectúan Lara Garrido y Jesús M. ${ }^{a}$ Morata Pérez $^{5}$ con la que realizan Alonso-Ferreres ${ }^{6}$, se gana en fiabilidad filológica (no total, como luego se verá), ya que el texto de Morata, y, por ende, el que reconstruye Lara Garrido en su artículo $^{7}$, se erige en un texto compuesto con limpia corrección, porque, por poner un detalle significativo, hasta la edición del profesor Morata Pérez, en ninguna de las publicaciones de este poema examinadas por mí, desde que fuera impreso en 1950 por D. Alonso y R. Ferreres, figura el sintagma «El fin» ${ }^{8}$ al final del texto, además de otros pormenores ecdóticos.

Pero, antes de entrar en materia, recordemos lo que sobre la autoría, la fecha y los rasgos textuales del poema han escrito y dicho Dámaso Alonso y Lara Garrido, principalmente. En primer lugar, todos los estudiosos y críticos (naturalmente, porque así lo dejó escrito Ignacio de Toledo y Godoy) han adjudicado el poema al doctor De Tejada Páez. Así, Alonso-Ferreres: «Del Dr. Agustín de Tejada» (1950: 425); Lara Garrido comienza su artículo de este modo: «Entre las composiciones de Agustín de Tejada recogidas en el Cancionero antequerano ninguna concita el interés que la extensísima (838 versos) narración, que hibrida épica religiosa y canción heroica, acerca de la Virgen de Monteagudo» (1995:139); y del mismo modo, Morata Pérez, en su edición electrónica (2008: 120), indica: «Del Doctor Agustín de Tejada». En

1 ALONSO, Dámaso; FERRERES, Rafael. Cancionero antequerano. Madrid: Consejo Superior de Investigaciones Científicas, 1950.

${ }^{2}$ LARA GARRIDO, José. Cancionero antequerano I. Málaga: Diputación Provincial, 1988.

${ }^{3}$ Para un mayor conocimiento de este autor, vid. Belén Molina Huete. «Agustín de Tejada y las Flores de poetas ilustres de Pedro Espinosa». Analecta Malacitana, 2001, XXIV, 2, pp. 353-402.

${ }^{4}$ LARA GARRIDO, José. «Un audaz experimento métrico de Agustín de Tejada Páez». En Silva Antequerana (II). Revista de Estudios Antequeranos III, 1, 1995, pp. 139-147. (Obvio la edición que del mismo publicó Íñiguez Barrena (1989: 123-147), por mantener los mismos errores que Alonso-Ferreres, aparte de otras fallas.)

${ }^{5}$ MORATA PÉREZ, Jesús. Agustín de Tejada en las Antologías contemporáneas. Edición electrónica [revisada el 29-12-2008], pp. 120-143.

${ }^{6}$ ALONSO, Dámaso; FERRERES, Rafael. Cancionero antequerano. Ob. cit., pp. 425-449.

${ }^{7}$ LARA GARRIDO, José. «Un audaz experimento métrico de Agustín de Tejada Páez». Art. cit., pp. 139-140. 
segundo lugar, sobre la fecha de composición, D. Alonso supone que fue escrito «por 1608» (1950: XX), porque cree que fue compuesto para presentarlo a las justas literarias celebradas con ocasión de la llegada a Antequera de la imagen de la Virgen de Monteagudo; por el contrario, Lara Garrido piensa que la composición del poema es posterior a dicha fecha, basándose en las referencias textuales de los sonetos del poeta antequerano Luis Martín de la Plaza y en otros pormenores del poema (1995: 142). Sin embargo, no propone fecha alguna. Y, en tercer lugar, en cuanto al texto, D. Alonso lo caracteriza como una «retahíla de versos» y que sólo «se anima en la descripción de la gruta del Guadalhorce, llena de aguas heladas, vahos que se condensan en preciosos cristales, cuadro colorista, que claro está, tiene el antecedente de la Fábula del Genil, del más joven Pedro Espinosa ${ }^{9} »$; y sigue diciendo: «debió de ser obra de encargo», escrita con «apremio», «casi a vuela pluma», que «revela la precipitación» (1950: XX-XXI). En cambio, la hipótesis de Lara Garrido es ésta: « [...] aunque resultara de un encargo, el poeta tuvo a la vista las composiciones presentadas a la justa, y se propuso realizar una especie de compendio mitopoético que acogiese y superase cuanto hasta entonces se había cantado de la Virgen de Monteagudo. Un compendio tensado por la intencionalidad de experimentación cultista, según hay que deducir de la meditadísima y equilibrada estructura correlacionada al manejo combinado de dos formas métricas (la octava real y los parágrafos de desigual longitud, compuestos de endecasílabos blancos a los que cierra un pareado ) para funciones temáticas y retóricas diferenciadas» (1995: 143). Y sigue escribiendo en ese mismo párrafo: «[...] Tejada lleva a cabo un innovador experimento métrico y formal, sin duda el más interesante de los acogidos en el Cancionero»(1995: 143).

\footnotetext{
${ }^{8}$ Alguien se podrá preguntar qué importancia presenta esa nimiedad. Desde un punto de vista lingüístico, este elemento es importantísimo, porque, amén de ser el editor o el antólogo fiel al original, ¿qué poeta, al acabar su poema, corona con un «El fin» el texto? Ninguno, a no ser que esté copiando o traduciendo otro texto primitivo donde sí se refleja tal hecho, según señalaré más adelante.

${ }^{9}$ El panegírico de Juan de Aguilar tiene ciertos elementos comunes con el «Romancillo al vulgo de Antequera explicándole la presencia de Nuestra Señora de Monteagudo» de Pedro Espinosa, que pudo presentar a la justa por tal motivo. Entre otras coincidencias, podemos destacar: la referencia a la madre Magdalena de san Jerónimo, dama de la infanta Isabel Clara Eugenia, la presencia de la metáfora de los cuernos de la luna, el nombre del río Escalda, la luz del piropo (en el sentido de 'aleación de cobre y oro'); sintagmas parecidos: belga hereje, versos los cisnes cantan, la alusión al roble bajo el que estuvo la imagen de la Virgen, etc., etc. Naturalmente, términos parecidos los descubrimos también en otros textos, como, por ejemplo, en los de Luis Martín de la Plaza, etc. (Vid. Pedro Espinosa. Poesías completas. Madrid: Espasa-Calpe, 1975, pp. 47-50. López Estrada, Francisco (ed. pról. y notas). Y Lara Garrido, José. Cancionero antequerano I. Ob. cit., pp. 83-86.) Vid., asimismo, Molina Huete, Belén. Tras la estela del mito. Texto y recepción de la Fábula del Genil de Pedro Espinosa. Málaga: Universidad de Málaga, 2005.
} 
Pues bien, gran parte del edificio construido por estos estudiosos no se sustenta a causa del hallazgo de la obra de Juan de Aguilar De Sacrosanctae Virginis Montis Acuti translatione et miraculis panegyris. Veamos las razones de nuestra tesis.

\section{LOS TEXTOS ${ }^{10}$}

\subsection{La autoría}

El poema, como hemos adelantado, no pertenece a Agustín de Tejada Páez, sino a Juan de Aguilar, porque el texto es una traducción del panegírico De Sacrosanctae Virginis Montis Acuti translatione et miraculis panegyris con algunas incrustaciones poéticas pertenecientes al estro lírico de Tejada o al de otros miembros del grupo antequerano-granadino, como luego probaremos. Por ello, tienen poco fundamento las dos primeras premisas, aunque la conclusión sea verdadera, sostenidas en el siguiente párrafo acerca de la traducción, en prosa o en verso: «[...] Sin temor a cualquier tipo de crítica, nos permitimos afirmar categóricamente que un poeta-imitador puede ser un autor original, aunque no escribiera nada por sí mismo. El traductor en prosa es un esclavo; el traductor en verso es un rival... El poeta original se enciende por un ideal, que encuentra en su imaginación; el poeta-imitador se inspira en la misma medida por su prototipo, que ocupa en él el lugar de su propio ideal: por consiguiente, el traductor, cediendo a su prototipo la prioridad de la ficción, debe poseer imprescindiblemente una imaginación casi idéntica a la suya, un estilo idéntico, una idéntica fuerza de la mente y sentimientos» ${ }^{11}$. ¿Podemos afirmar, en consecuencia, que cualquier buena traducción en verso de la Farsalia, pongo por caso, corresponde al traductor y no a Lucano? Del mismo

${ }^{10}$ Me serviré para mi estudio y análisis, en el caso del texto de Agustín de Tejada Páez, de la edición electrónica publicada por Jesús $\mathrm{M}^{\mathrm{a}}$ Morata Pérez en su web, además de haber tenido presente la de Alonso-Ferreres. A dicho poema lo llamaré (Texto B). Para el texto latino de Juan de Aguilar me valdré del texto publicado en 1609, custodiado en la biblioteca de la Universidad de Sevilla, con las correcciones oportunas realizadas por mí. (Vid. Aguilar, Juan de. De Sacrosanctae Virginis Montis Acuti translatione et miraculis panegyris. Málaga: Juan René, 1609). A este texto lo denominaré (Texto A). De la misma forma, como considero que la extensión de los dos textos rebasaría los límites de un trabajo de esta naturaleza, remito a una directa lectura de dichas composiciones, cuyo acceso es hoy muy fácil. Para ello, basta con entrar en las web correspondientes de Jesús $\mathrm{M}^{\mathrm{a}}$ Morata Pérez y de la biblioteca universitaria de Sevilla. No obstante, usaré algunos fragmentos de los mismos como prueba de la tesis mantenida en este artículo.

${ }^{11}$ YUKOVSKI, V. A. «Sobre la fábula y las fábulas de Krylov», ap. VV. AA. Teorías de la traducción. López García, D. (ed.). Cuenca, 1996, p. 124. (Vid. Carreira, A., «Luis Martín de la Plaza, o el manierismo en Antequera». En Analecta Malacitana, XX, 1, 1997, pp. 291-306.) 
modo, ¿se podrá juzgar del prebendado antequerano-granadino un texto, si bien modificado en la métrica con respecto al opúsculo de Juan de Aguilar, con digresiones y paráfrasis, y que casi triplica la extensión del original, cuya estructura y contenido son equivalentes a los de la obra que traduce? Ciertamente no, pese a la labor de taracea llevada a cabo por Agustín de Tejada Páez. Por tanto, la deuda de la canción del doctor Tejada con la obra del humanista ruteño es indudable, porque, comparando ambos textos, se detecta que Agustín de Tejada no sólo imita, sino que plagia la estructura externa, el contenido y el argumento en aquellos momentos de la canción en que no se sale del patrón original.

\subsection{Argumento y estructura del contenido tanto del Texto A como del Texto B}

Como la imagen de la Virgen de Monteagudo, debido a las guerras sostenidas en Flandes, está en peligro de ser profanada, Isabel Clara Eugenia, hija de Felipe II, ordena que sea traída a España, concretamente a Antequera. Para ello se vale de la madre Magdalena de san Jerónimo, que la rescata de las manos de los herejes y protestantes de la fe católica. Durante el traslado, como anteriormente a él, a la Virgen le atribuyen una serie de milagros, metamorfoseándolo todo. Una vez llegada a la ciudad malagueña, el pueblo entero exulta de alegría por su presencia, e incluso el paisaje antequerano, como el Guadalhorce, le rinde honores y los poetas le cantan en sus versos. Colocada la imagen en el convento de la Madre de Dios de Antequera, la gente celebró aquellos actos con gran júbilo.

Juan de Aguilar articula el panegírico a semejanza de la organización de cualquier sermón o panegírico de la oratoria sagrada, que nos recuerda la estructura tradicional de exordio, desarrollo y desenlace o conclusión, en un tono propio de la graviditas latina, por oposición al elogio que está impregnado casi siempre de la humilitas. Así, los nueve primeros versos (1-9) ocupan la parte exordial: nace la metamorfosis, se invoca con el apóstrofe a la Virgen y se interpela al corregidor Diego del Castillo, como mecenas, para que acoja los versos que va a cantar el poeta. A partir del verso 10 y hasta el 335 tiene lugar el cuerpo del panegírico: el traslado de la Virgen desde Flandes a Antequera. Desde el verso 336 hasta el 361 le sirven a su autor para cerrar el texto: la Virgen disfruta ahora de un lugar seguro. Ahora bien, dentro de la parte troncal pueden detectarse otros subapartados: Ubicación del Monte Agudo (10-21); erección del santuario y veneración a la Virgen (22-41); la Virgen, protección y medicina de los católicos, ayuda a vencer a los enemigos de la fe católica (42-64); proclamación de los milagros de la Virgen (65-86); pone por testigo de ello a la madre Magdalena de san Jerónimo (87-109); referencia a los milagros en relación con la gente del mar (110-125); vuelta al escenario de operaciones bélicas y salvación de la imagen (126-170); intervención del ar- 
chiduque Alberto y de Isabel Clara Eugenia, y canto al linaje real (171-191); traslación de la imagen de la Virgen a España (192-246); y llegada a Antequera y fiesta en su honor (247-335).

Los mismos pasos pueden percibirse a través de los 838 versos de A. de Tejada Páez, salvando los momentos en que se separa del hilo del texto de J. de Aguilar.

\subsection{Fecha de composición}

Comparando ambos textos, se detecta que tanto Dámaso Alonso, como Lara Garrido yerran cuando fechan el poema de Agustín de Tejada Páez, porque, si se parte de que este texto es una traducción, literal a veces, libérrima otras, como luego tendremos ocasión de probar, del panegírico de Juan de Aguilar, el poema del humanista ruteño fue orado por él mismo el 18 de octubre de 1608 en el convento de la Madre de Dios de Antequera, según se desprende de la advertencia del autor al lector: IN CELEBRI ILLO POE-/ tarum agone, qui nuper apud nos An-/ tiquariae editus est in laudem Sacro-/ sanctae Virginis Aspricollis, de transla-/ tione, deque innumeris, clarissimisque ipsius mi-/ raculis in augustissimo eiusdem templo Panegy-/ rim hanc illustrissimo nostro praesuli, et civitaI ti recitaveram universae. Eam in praesenti offe-/ ro tibi, pie lector, ut simul et felicitate nostra,/ qui talem nacti sumus Praesidem gaudere, et/ Deiparae Virginis laudibus frui possis. Fruere,/ et vale ${ }^{12}$; igualmente, como, según se colige de la licencia de impresión del libro (fol. 2r), la obra de Juan de Aguilar estaba lista para imprimir el dos de junio de 1609, año de su publicación, el poema de Agustín de Tejada pudo ser compuesto entre octubre de 1608 (si es que el doctor Tejada dispuso ya de alguna copia manuscrita del panegírico, así como de otros textos escritos para la ocasión por diferentes miembros del grupo antequerano-granadino, cosa improbable por las características propias de una justa literaria) y un tiempo muy cercano a la publicación de De Sacrosanctae Virginis Monstis Acuti translatione et miraculis panegyris. Por tanto, con el hallazgo de la obra del humanista se esfuman todas las elucubraciones y apoyaturas argumentales de D. Alonso o J. Lara Garrido, sobre todo, en el sentido de que ni fue compuesta por encargo alguno, ni fue escrita por Tejada para presentarla a la justa de 1608, con ocasión de la traslación de la Virgen de Monteagudo

\footnotetext{
${ }^{12}$ AGUILAR, Juan de. De Sacrosanctae Virginis... Ob. cit., fol. 3r, que traduzco así: «En aquella célebre justa poética, que recientemente entre nosotros, en Antequera, se ha publicado en alabanza de la sacrosanta Virgen de Monteagudo sobre su traslación e innumerables y clarísimos milagros, en su majestuosísimo templo, había pronunciado yo este panegírico en presencia de nuestro ilustrísimo obispo y de todo el pueblo. Ahora te lo ofrezco a ti, querido lector, para que, al mismo tiempo y con nuestra felicidad, quienes somos sus naturales, puedas gozar de tal Protector y disfrutar de las alabanzas de la Virgen Madre de Dios. Aprovecha, y vale».
} 
desde Flandes a Antequera, ni escrita con apremio, etc. Tampoco vale afirmar que la composición (en tanto que poema creado por Tejada Páez) fue posterior a dicho año, como defiende Lara Garrido, porque haya referencias que evidencian posterioridad al evento, pues dichas alusiones están presentes en la obra latina de Juan de Aguilar, como lo atestigua una lectura comparada entre los mismos. Lo único verosímil, pues, es que Tejada Páez ejecutó su traducción hipertextual a partir de 1609, cuando pudo tener delante el impreso o copias de los textos en que se basó él para escribir el suyo, pero no muchos años después de esa fecha.

1.4. Texto A vs. Texto B: Consideraciones sobre su estructura, fuentes y rasgos lingüístico-literarios

Poniendo frente a frente los dos textos, se detecta que el Texto A se desarrolla a lo largo de 361 hexámetros, como sabemos, en tanto que el Texto B posee 838 endecasílabos, distribuidos en dos formas métricas: octavas reales y paraestrofas de desigual extensión compuestas por endecasílabos blancos. La elección que del metro realiza Tejada Páez para traducir el hexámetro latino no es la que exige el original, porque el hexámetro requiere, salvando los obstáculos rítmicos, el alejandrino español, aunque éste, como bien se conoce, prácticamente desaparece en el siglo XV, para resurgir con esplendor en el siglo XIX. (El modelo italiano se impuso en el Siglo de Oro como verso culto.) El hecho es un fracaso y no «un innovador experimento métrico y formal» (Lara Garrido, 1995: 143), porque no supera la obra del humanista ruteño, si es que Tejada Páez se propuso llevar a cabo un acto creador. Tampoco, desde un punto de vista de la coherencia, es un poema perfectamente articulado, pues cuando se sale del patrón latino, el traductor se pierde en excursos, paráfrasis y cuñas personales que desvirtúan el núcleo argumental del Texto A. De ahí que le dé la razón a Dámaso Alonso cuando afirma que el Texto B, del poeta antequerano-granadino, es una «retahíla de versos» (1950: XX-XXI), con pretensiones de originalidad.

Siguiendo con nuestra incursión, el lector percibirá inmediatamente que el Texto B carece de la cabecera con que empieza el Texto A: De Translatione et mi-/ raculis Sanctissimae Virginis Montisacuti / Ioannis Aquilarii Panegyris $^{13}$. El hecho se debe, seguramente, al traductor, que la escamoteó, porque en un caso similar I. de Toledo y Godoy notifica que el soneto recogido es una traducción del epigrama de Pontano ${ }^{14}$ llevada a cabo por Agustín Cal-

${ }^{13}$ Traduzco ese epígrafe de este modo: «Panegírico de Juan de Aguilar sobre la traslación y milagros de la Virgen de Monteagudo».

${ }^{14}$ Así, al recopilar el soneto 167, informa: «Pontani. 2 t[tomo], Dial[ogo] Ant[oni]o. Carmen: «Dulce dum ludit Galatea in unda». L[icencia]do Calderón traduce. Soneto 167.» (Vid. Lara Garrido, José. Cancionero antequerano I. Ob. cit., pp. 121 y 304-305.) 
derón. Otra prueba a favor del antólogo estriba en que, aunque él se considere un «aficionado» [...] «que copió... composiciones que le interesaban sin otra intención que complacerse en su lectura» (Lara Garrido, 1988: 25 y nota $\mathrm{n}^{\circ}$ 48), ha «leído las más y peregrinas obras que manuscriptas he podido haber a las manos» (Lara Garrido, 1988: 25). Por tanto, Tejada, al eliminar, probablemente (esta suposición es válida hasta tanto no se halle el manuscrito primigenio del prebendado antequerano), en su texto la traducción del título y el nombre del autor de la obra, se atribuye una obra que no le pertenece. En cambio, si Tejada no tradujo el encabezamiento del poema, fue fiel al cierre del mismo, ya que corona la traducción con un «El final» ${ }^{15}$, que no hace sino reflejar el Finis con que acaba el panegírico aguilariano. Por eso, es extraño que esta particularidad, insignificante pero bien elocuente, no les haya llamado la atención ni al antólogo, ni a los estudiosos y editores modernos del poema, para sospechar sobre la autoría y el carácter del mismo, pues ¿qué poeta coloca a la conclusión de un poema un «Fin», a no ser que haya que advertir al lector que no confunda el panegírico con tres epigramas, también escritos por Juan de Aguilar, que figuran a continuación y que tratan sobre el mismo asunto?

Tras la cabecera, el cuerpo del Texto A comienza con los hexámetros IN nova fert pietas matrem celebrare Tonantis / Templa peregrinis translatam sedibus axis / Parrhasii ad veterem, rapidi quae Singilis, urbem / Nomen habet [...], que remiten inmediatamente a la fuente ovidiana ${ }^{16}$, sin perder de vista a Virgilio $^{17}$. Pues bien, Tejada Páez parece más bien traducir el sentir de Ovidio que el sentimiento piadoso que reflejan dichos versos del panegírico del humanista ruteño. El Texto $\mathrm{B}$, del poeta antequerano, los traduce casi al pie de la letra de esta manera: «El ánimo me inflama ardiente celo / de celebrar la traslación gloriosa / de la alta Emperatriz de tierra y cielo, / traída a nuestra patria venturosa». El vocativo Tu, Virgo, fave, del cuarto hexámetro del Texto A, le servirá al traductor para componer la primera de sus amplificatio, cuyo endecasílabo «libre de los naufragios, el piloto» (pie de glosa de la justa poética celebrada en Antequera para conmemorar la llegada de la imagen de la Virgen de Monteagudo desde Flandes a la ciudad malagueña) cierra la segunda octava real de que se compone el Texto B. Ese mismo ende-

${ }^{15}$ Este sintagma lo he detectado, de las ediciones consultadas por mí, sólo en la de Jesús $\mathrm{M}^{\mathrm{a}}$ Morata Pérez. Dámaso Alonso-Rafael Ferreres y otros editores lo silencian.

${ }^{16}$ Compárense esos versos de Juan de Aguilar con los que comienza el libro I de las Metamorfosis de Ovidio: «In nova fert animus mutatas dicere formas / corpora; di, coeptis (nam vos mutastis et illas)», para percatarse del hecho. Vid. Tarrant, R. J. P. Ovidi Nasonis Metamorphoses. Oxford: Oxford University Press, 2004; Publio Ovidio Nasón. Metamorfosis. Ruiz de Elvira, A. (Texto y trad.). Salamanca: CSIC, 1992, 3 vols.

${ }^{17}$ Virgilio es fuente de inspiración en esta obra de Juan de Aguilar, principalmente en cuanto a sus Geórgicas, sobre todo en aquellos detalles que le permiten ejercitar su sensibilidad artística. Vid. Publio Virgilio Marón. Bucólicas. Geórgicas. Apéndice virgiliano. Madrid: Gredos, 1990. 
casílabo será pie de glosa para concluir tres octavas reales más: las de los versos 750, 758 y 766, respectivamente, que constituyen otras desviaciones con respecto al Texto A. Por ello, es probable que Tejada Páez se presentara al certamen poético con esas octavas y posteriormente las incrustara en su traducción, pues se alejan muchísimo del panegírico aguilariano. Más aún, las coincidencias entre los dos textos en esa parte se reducen a unos sintagmas iguales.

Asimismo, el Texto B adolece de ciertas incorrecciones o lecturas imprecisas con relación al Texto A, imputables bien al traductor, bien al antólogo (si no son debidas a los editores ${ }^{18}$ ). De esas lecturas erróneas destacaré las siguientes, por ser las más llamativas y por distorsionar el sentido último del texto latino y el del texto vertido al castellano. Así, el hexámetro 49 y parte del 50 del Texto A: Inter mille vias leti, discriminis inter / mille modos, es leído en el Texto B (vv. 108-109) como: «Y entre caminos mil de varias fuentes / y modos mil», según la edición del profesor Morata Pérez ${ }^{19}$, pero Dámaso Alonso y Rafael Ferreres, con buen criterio filológico, imprimen «Y entre caminos mil de varias suertes / y modos mil» ${ }^{20}$, puesto que traducen mejor el término latino leti, así como discriminis = 'ruina, muerte, destrucción', y 'diferencia, distinción, peligro, situación crítica'. Por consiguiente, en este punto concreto es mejor leer con Alonso-Ferreres que con Morata Pérez.

El hexámetro 117 del Texto A, Neptunique minas cohibes; verumque tridentem es traducido incorrectamente en el Texto B por los vv. 234-235: «Porque tú sola eres quien aplaca / las fieras amenazas de Nereo». Habría sido más acorde «Neptuno», que es un personaje mitológico distinto al dios del mar Nereo, como luego advierte Juan de Aguilar en los hexámetros 119-120: Te colit ipse pater Nereus, quem falsa marinum / Fama canit regem, que son traducidos correctamente, pero contradiciéndose con el sentido de los versos precedentes, de esta forma (vv. 240-241): «Nereo mismo, a quien la falsa fama / por rey del mar invoca, se te rinde» ${ }^{21}$.

Exactamente igual, el hexámetro 120 del Texto A se completa con estas palabras teque et Portunus adorat, que se traduce en el Texto B con un valor dislocado (v. 242): «importuno también tus plantas besa». El traductor o el antólogo no sabían qué estaban leyendo, porque, como bien se sabrá, Portu[m]nus es el dios de los puertos, que es el que también «se te rinde, te adora». No viene, por tanto, al caso el término de «importuno».

\footnotetext{
${ }^{18}$ Afirmo esto porque no he podido tener acceso personal al manuscrito del Cancionero antequerano.

${ }_{19}$ Vid. Agustín de Tejada en las Antologías contemporáneas. Ob. cit., p.123.

${ }^{20}$ ALONSO, Dámaso; FERRERES, Rafael. Cancionero antequerano. Ob. cit., p. 428.

${ }^{21}$ Morata Pérez, en su edición, en nota escribe: «V. 240: el ms. lee con signos de paréntesis «Nereo mismo (a quien la falsa fama)». ¿Estaría señalando Ignacio de Toledo y Godoy con esos signos que es un verso exacto al hexámetro aguilariano?
} 
El verso latino 202 Sub terris tibi pandis iter trepidansque pudore es leído mal por Morata en su edición. Allí opta por una versión errónea (la que lee el ms.). Así, el v. 426 del Texto B, que traduce el sentir del verso latino anterior, dice: «no por cima la yerba entapizada», etc. De acuerdo, pues, con el original latino y con el texto de Tejada Páez, es más fiel leer con Alonso-Ferreres: «no por cima la tierra entapizada», puesto que recoge la idea de $s u b$ terris («bajo tierra»), o sea, «no por cima la tierra», que con Morata o que con el manuscrito. Con la lectura del ms. y la de Morata se cae en una contradicción: «no por cima la yerba entapizada / de aljofaradas yerbas y de flores».

Los hexámetros 203-205 del Texto A dicen: O Demera infelix, rauco cum murmure vectus / In patrem Scaldim, moestis inglorius undis / influis [...], que son leídos en el Texto B (vv. 425 [...] y 434, según todos los editores que han tenido acceso al manuscrito, como: «Tu Démara, también ínclito un tiempo / [...] pagas al padre Escalda mudo censo». Es obvio, porque lo exige la concordancia tanto del verbo latino influis, como la de las formas verbales españolas «llevas», «solías», «gozabas», «verás» y sobre todo «pagas al padre Escalda mudo censo», que el «tu» no es un determinante posesivo de «Démara», sino el pronombre personal de segunda persona «tú», seguido del vocativo $O$ Demera infelix. Así pues, una lectura correcta actual debería decir: «Tú, Démara...». La mala lectura de los editores denuncia que no han entendido el sentido de esos versos, aunque creo que sí I. de Toledo y Godoy, porque, al no estar aún en su época normalizada la ortografía, se limitó a transmitir el sentido original.

El v. 227 latino Ast ubi pervenit, qua sese excelsa Pyrene, que es traducido por el verso 509 «Pero cuando llegó la Virgen ínclita», no hace sino ser fiel al verbo latino pervenit. Por tanto, la nota de Morata, quien imprime «llegó», y no «lleuo», como lee el manuscrito, se reduce a seguir el sentido lógico. (Alonso-Ferreres corrigen la lectura del ms., pero no lo advierten.)

Los versos 230-231 del Texto A leen: Relligione pia venerabile numen adorans; / Exaequat planis sublimia culmina campis:, que son traducidos libremente en los versos 519-523 del Texto B como: «de religión movido el gran Pirene, / por adorar la imagen de María, / a las faldas más llenas y tendidas / de sus riscos las máquinas iguala / y al cielo les dan paz con gran soberbia,». Pues bien, Morata Pérez, en la nota 158 escribe: «V. 521: en el ms. se lee llenas; Alonso-Ferreres imprimen llanas (que resulta allí redundante).». Con el Texto A en la mano, es evidente que Ignacio de Toledo y Godoy realiza una lectura incorrecta del original de Tejada Páez, si éste tradujo bien la palabra planis. Por eso, la versión de Alonso-Ferreres es la correcta y no la de Morata Pérez, aunque exista un pleonasmo. Asimismo, también lee mal el ms., al emplear el pronombre personal de tercera persona plural «les», en vez del singular «le». La relación sintagmática exige «le». En consecuencia, imprimen bien también en este caso Alonso-Ferreres. 
El verso 465 del Texto B es leído en la edición de Morata como «los bellos bultos de los blancos cuerpos;». Alonso-Ferreres, en cambio, escriben: «los bellos vultos de los blancos cuerpos;». De acuerdo con el texto de Juan de Aguilar, dicho verso no puede ser leído como procede Morata, y sí como lo interpretaron Alonso-Ferreres (aunque no adujeran pruebas), porque el término vultus latino implica aquí el significado etimológico de «rostro», «cara», y no el de «cuerpo». Si se aceptara el razonamiento de Morata ${ }^{22}$, se caería en una aporía: «los bellos bultos (cuerpos) de los blancos cuerpos». En cambio, la propuesta de Alonso-Ferreres es más lógica, a tenor del sentido que Juan de Aguilar concede a dicho vocablo en su texto, el de «rostro», «cara», «expresión», «aspecto», como puede verse en los versos Purpureo sacrat vultu, quem pronus adorat (36), Hinc progressa, pios vultu Virgo inclita Iberos (234), Ut vero sacri vultus nova lumina sensit (247) y Laeti animis, laeto testantes gaudia vultu. (298).

El v. 545 es leído por Morata, quien sigue la versión del ms., como «alegre recibistes a la Reina». Alonso-Ferreres, en cambio, editan «alegres recibisteis a la Reina». Con la primera lectura, la alegría sólo es propia del Tajo; por el contrario, con la segunda, es compartida por los demás ríos. Esta interpretación es más adecuada al sentido del original latino (vv. 236-242), que dicen: ../ Durius in primis celebris regnator aquarum / Hesperiae, tuque auratas qui volvis arenas, / O Tage, splendori vos ostentatis Olympi. (Fíjense en el pronombre personal vos y en el verbo ostentatis, cuyos elementos anafóricos son el Ebro, Duero y Tajo.)

Por último, para no ser más prolijo, pues pienso que con esas anotaciones ha quedado lo suficientemente probado que no nos hallamos ante un caso de adopción de formas y de contenido, sino ante una traducción, señalaré algunos otros cotejos entre los dos textos para valorar la filiación del texto de Tejada con relación al de Juan de Aguilar:

Texto A

Texto B

1) Los nueve primeros versos del texto latino le sirven al autor de la canción para componer los veinticuatro primeros de la suya, pero siguiendo la estructura del texto latino (adviértase igual léxico, misma estructura, idéntico contenido):

${ }^{22}$ Morata escribe: «En los v. 464-5, Alonso Ferreres cometen dos errores de interpretación. El primero consiste en leer «... y a las Hémmides», en lugar del correcto «...ya las Hénides», porque estas ninfas son el sujeto (no el complemento indirecto) del verbo niegan. El segundo error es entender los bellos bultos del ms. en la acepción de «rostros, caras» (vultos). El contexto indica sin ninguna duda que el poeta se refiere a los «cuerpos» (bultos) de las ninfas: a consecuencia de la traslación de la imagen a Antequera, el monte agudo flamenco pierde todo su esplendor; incluso las Hémmides (hénides) les niegan ya a los prados la presencia de sus bellas formas corporales.» (2008: 133, nota). Su argumentación es correcta para deshacer el primer error. Pero se torna falaz en el segundo caso, según hemos justificado. 
In nova fert pietas matrem celebrare Tonantis Templa peregrinis translatam sedibus axis Parrhasii ad veterem, rapidi quae Singilis, urbem Nomen habet. Tu, Virgo, fave; te nostra Thalia Laeta canit supplexque tuo se addicit honori. Tu, Virgo, mihi carmen eris, dum vita manebit. Tuque, o magne parens, insignis gloria nostri Saeculi, et Aonidum Mecaenas inclite, coeptis Adspirato meis et Virginis accipe laudes.

\author{
El ánimo me inflama ardiente celo \\ de celebrar la traslación gloriosa \\ de la alta Emperatriz de tierra y cielo, \\ traída a nuestra patria venturosa. \\ Tú, excelsa Virgen, da a mi pluma vuelo, \\ que aspira a empresa tan dificultosa \\ que tú serás mi musa, lauro y palma, \\ mientras rigiere a aqueste cuerpo el alma. \\ Tú, intacta Virgen, musa sacra y bella,
}

Tú, ínclito don Diego, honor y gloria de nuestros siglos, y mecenas santo de espíritus gentiles, cuya historia celebra tanta pluma y cisne tanto, entre una y otra célebre memoria presta lugar a mi atrevido canto; oye de la cristífera María los loores que entona mi Talía.

\section{2) Los diez siguientes hexámetros de Juan de Aguilar son traducidos en los versos 25-39 del texto del prebendado antequerano-granadino, se- gún esta comparación, casi ad pedem litterae, como ocurre en otros momentos del texto:}

Caerula in angustum qua cogitur Amphitrite Et pater Oceanus saevit fluctuque sonanti Verberat a Christi divisos orbe Britannos; Qua, Germane ferox, Erymanthida suspicis ursam Aethere pendentem summo capitique minantem; Et Musam Scaldimque inter, celeberrima Belgis Flumina, Sichemum iuxta, Demeraeque liquentes Propter aquas, medioque tui Brabantica tellus, Asper in immensum collis se attolit Olympi Aemulus, aethereoque illudit vertice nubes Arduus aerias, supremaque sidera pulsat, Ut monti asperitas dederit cognomen Acuto.
Donde Anfitrite su corriente estrecha y se embravece; el grande padre Oceano azota con sus olas resonantes los britanos del mundo divididos; en la parte que miran los germanos sobre sus cabelleras de oro rubio los Triones helados y pluviosos y la arcádica Osa, que al dios Júpiter regalo un tiempo fue y a Juno celos; entre el Mosa veloz y helado Escalda, celebérrimos ríos del flamenco; no lejos de Siquén ya, pueblo noble, donde en Brabancia el Démara dilata en crespas ondas fugitiva plata:

3) Existen múltiples casos en que A. de Tejada Páez no se sale del camino trazado en el texto del humanista ruteño:

Ut quae mortiferi caput exitiale Draconis

Fregerat, haec eadem, primae vetus ulta parentis
Para que la que había quebrantado la cabeza mortal del dragón fiero, esta misma vengase la ignominia 
Vertice in hoc igitur Virgo medicina, salusque Exstitit aegrorum communeque gentis asylum Pugnarumque graves casus horrentiaque inter
En este monte, pues, fue la alma Virgen medicina y salud a los fieles y muro inexpugnable a los que siguen

4) Otras veces el texto tejadiano no puede prescindir de nombres propios de ríos, montes, personajes históricos, etc., siendo fiel al texto aguilariano:

Rhenus ut Archiducis cognovit iussa, suumque Dedecus, Hesperii queritur sibi Baetidos oras

O soboles dignissima laude parentum Immensa! O Caroli proles! O nata Philippi!
El Rin, que oyó que el Archiduque Alberto manda que quede agora despojado de la sagrada imagen de María y que del Betis las riberas corvas,

¡O $h$ vos, ínclita y clara descendencia de Carlos Quinto, nuevo Marte Augusto! $¡ O h$ tú, Clara Isabel, cuya presencia

5) La canción del Texto B acaba exactamente igual que el Texto A:

Hac fatuus tremefecit aquas rex magnus, at illi Assensere omnes dictis plaudentibus alis, Ostendensque Dei praecepta facessere promptum In nidum celeri recipit se quisque volatu.

FINIS
Dijo, y todos partieron al momento a obedecer su oráculo y mandato, y con sus voces penetrando el viento del Parnaso hicieron un retrato: cuál celebra la Virgen en su acento, cuál el laurel del escuadrón beato que son, con roja púrpura y martirio, rojos claveles del jardín impirio.

El fin.

6) En consecuencia, el estudio comparativo entre el Texto A y el Texto $\mathrm{B}$ arroja a grandes rasgos las siguientes correspondencias:

$\begin{array}{lll}\text { vv. } 1-9 & \text { / } & \text { vv. } 1-24 \\ \text { vv. } 10-25 & / & \text { vv. } 25-54 \\ \text { vv. } 26-41 & / & \text { vv. } 55-82 \\ \text { vv. } 42-55 & / & \text { vv. } 83-124 \\ \text { vv. } 56-125 & / & \text { vv. } 125-260 \\ \text { vv. } 126-170 & / & \text { vv. 261-355 } \\ \text { vv. } 171-191 & / & \text { vv. } 356-398 \\ \text { vv. } 192-212 & / & \text { vv. 399-471 } \\ \text { vv. } 213-219 & / & \text { vv. } 472-488 \\ \text { vv. } 220-226 & / & \text { vv. } 489-508 \\ \text { vv. } 227-236 & / & \text { vv. 509-535 } \\ \text { vv. } 237-246 & / & \text { vv. 536-563 } \\ \text { vv. } 247-361 & / & \text { vv. 564-838 }\end{array}$


Según puede comprobarse, el traductor De Tejada Páez es más fiel al texto latino de Juan de Aguilar hasta el hexámetro 247 que en el resto del panegírico, donde se desvía del original. Igualmente, si, hasta ese hexámetro, ha necesitado 2,3 versos endecasílabos para cada verso latino, a partir del mismo ha empleado 2,4 endecasílabos para cada hexámetro. Ello significa, aparte de pasar de una lengua sintética - latín - a otra analítica — castellano o español-, que en este segundo tramo del texto el prebendado antequerano hace más uso de la paráfrasis que de la traducción, pese a las digresiones del primer trecho.

\section{CONCLUSIÓN}

Con el hallazgo que se ha llevado a cabo de la obra del humanista ruteño Juan de Aguilar De Sacrosanctae Virginis Montis Acuti translatione et miraculis panegyris y con estas calas comparativas realizadas en los dos textos se descubre que desde 1627-1628 se le ha asignado al poeta antequerano-granadino Agustín de Tejada Páez un poema que no le pertenece, ya que se trata de una traducción, en su núcleo central, del panegírico del maestro de latinidad. Asimismo, casi todo lo que han escrito Dámaso Alonso y el profesor Lara Garrido acerca del poema hay que modificarlo a la luz de los nuevos datos aportados en dicha obra. Igualmente, el análisis comparativo entre un texto y otro nos ayuda a realizar una nueva lectura de algunos momentos del texto del poeta antequerano-granadino Agustín de Tejada Páez. Por tanto, desde ahora habrá que aclarar que el poema que figura en el Cancionero antequerano cuyo primer verso es «El ánimo me inflama ardiente celo», como «Del Doctor Agustín de Tejada», es una versión al castellano del panegírico latino aguilariano, mas no un poema salido de su musa poética, en tanto que acto creador.

Fecha de recepción: 27 de enero de 2009

Fecha de aceptación: 1 de julio de 2009 